\title{
Hyperinsulinaemia: the key feature of a cardiovascular and metabolic syndrome
}

\author{
E. Ferrannini $^{2,3}{ }^{3}$, S.M.Haffner ${ }^{1}$, B.D. Mitchell ${ }^{1}$ and M.P.Stern ${ }^{1}$ \\ Divisions of ${ }^{1}$ Clinical Epidemiology and ${ }^{2}$ Diabetes, Department of Medicine, University of Texas Health Science Center at San Antonio, \\ San Antonio, Texas, USA, and ${ }^{3}$ Metabolism Unit of the C.N.R. Institute of Clinical Physiology, University of Pisa, Pisa, Italy
}

\begin{abstract}
Summary. In a population-based survey of 2,930 subjects, prevalence rates for obesity, Type 2 (non-insulin-dependent) diabetes mellitus, impaired glucose tolerance, hypertension, hypertriglyceridaemia, and hypercholesterolaemia were $54.3,9.3,11.1,9.8,10.3$ and $9.2 \%$, respectively. The prevalence, however, of each of these conditions in its isolated form (free of the other five) was $29.0 \%$ for obesity, $1.3 \%$ for Type 2 diabetes, $1.8 \%$ for impaired glucose tolerance, $1.5 \%$ for hypertension, $1.0 \%$ for hypertriglyceridaemia, and $1.7 \%$ for hypercholesterolaemia. Two-by-two associations were even rarer. The large differences in prevalence between isolated and mixed forms indicate a major overlap among the six disorders in multiple combinations. In the isolated form, each condition was characterized by hyperinsulinaemia (both fasting and $2 \mathrm{~h}$ after oral glucose), suggesting the presence of insulin resistance. In addition, in any isolated condition most of the variables categorising other members of the sextet were
\end{abstract}

still significantly altered in comparison with 1,049 normal subjects. In the whole of the subjects who presented with one or another disorder $(1,881$ of 2,930 or $64 \%)$, marked fasting and post-glucose hyperinsulinaemia was associated with higher body mass index, waist:hip ratio, fasting and post-glucose glycaemia, systolic and diastolic blood pressure, serum triglycerides and total cholesterol levels, and with lower HDL-cholesterol concentrations (all $p<0.001$ ). We conclude that (1) insulin sensitivity, glucose tolerance, blood pressure, body fat mass and distribution, and serum lipids are a network of mutually interrelated functions; and (2) an insulin resistance syndrome underlies each and all of the six disorders carrying an increased risk of coronary artery disease.

Key words: Hyperinsulinaemia, insulin resistance, syndrome $\mathrm{X}$, San Antonio Heart Study.
It has long been known that both hypertension and Type 2 (non-insulin-dependent) diabetes mellitus are often associated with overweight $[1,2]$, and that hypertension is more prevalent among diabetic than non-diabetic individuals [3]. Hyperlipidaemia (high serum triglyceride or total cholesterol concentrations or both) is found with increased frequency in both diabetic [4] and hypertensive patients [5]. Thus, there seems to be a substantial overlap of disturbances of carbohydrate and lipid metabolism and of blood pressure in the general population, although, to our knowledge, a formal analysis of such clustering has not appeared in the literature.

Recently, it has been suggested that hyperinsulinaemia may be the common element accounting for the association of obesity, Type 2 diabetes, and hypertension [6]. Obesity and Type 2 diabetes are classic states of insulin resistance [7], and recent evidence has shown that essential hypertension per se is often an insulin-resistant condition [8]. This has led Reaven [9] to hypothesise that insulin resistance aggregates with glucose intolerance, hyperten- sion, and dyslipidaemia in a distinct syndrome (syndrome $\mathrm{X})$.

Diabetes, hypertension, and hypercholesterolaemia are unquestioned risk factors for cardiovascular disease (CVD) [10], whilst the evidence linking impaired glucose tolerance to CVD is less consistent [11]. The Framingham study has also established that high triglyceride levels, when coupled with low high-density-lipoprotein(HDL)-cholesterol concentrations, carry an increased risk of CVD [10]. Finally, recent data from a large population-based, follow-up study indicate that overweight, even of a minor degree, is an independent risk factor for ischaemic heart disease in women [12]. On the other hand, in two prospective epidemiologic studies $[13,14]$ plasma insulin concentration has emerged as an independent predictor of coronary heart disease. On these grounds, it is logical to suppose that the putative hyperinsulinaemia/insulin resistance syndrome may be associated with an increased risk of cardiovascular morbidity. 
The present analysis of the San Antonio Heart Study database identifies and characterises an insulin resistance syndrome.

\section{Subjects and methods}

Subjects

The San Antonio Heart Study is a population-based study of diabetes and cardiovascular diseases in Mexican-Americans and non-Hispanic whites. From 1984 to 1988 households from several types of San Antonio census groups were randomly sampled: low-income census tracts ( $95 \%$ Mexican-American); middle-income tracts (50\% Mexican-American and $50 \%$ non-Hispanic white); and suburban census tracts (10\% Mexican-American, 90\% non-Hispanic white) [15]. Stratified random sampling was used in the middle-income and suburban census tracts to ensure the inclusion of approximately equal numbers of each ethnic group in the study sample. All men and nonpregnant women 25 to 64 years of age were eligible for the study.

Ethnicity was defined on the basis of a previously published algorithm which considered parental surnames and birthplaces, stated ethnicity of grandparents, and participant's preferred ethnicidentity when it indicated a distinct national origin [16]. Persons who were identified as belonging to an ethnic group other than MexicanAmerican or non-Hispanic white are excluded from the present analysis. The study was approved by the Institutional Review Board of the University of Texas Health Science Center at San Antonio, and all subjects gave informed consent.

\section{Procedures}

Anthropometric measurements (height, weight, and waist/hip circumference ratio, WHR) were made with each participant wearing only underclothes and an examination gown [15]. Body mass index

Table 1. Prevalence rates of obesity, Type 2 (non-insulin-dependent) diabetes, hypertension (HBP), impaired glucose tolerance (IGT), hypertriglyceridaemia (HTG), and hypercholesterolaemia $(\mathrm{HCH})$ in 2,930 subjects $^{2}$

\begin{tabular}{lcccccc}
\hline Prevalence & Obesity & $\begin{array}{l}\text { Type } 2 \\
\text { diabetes }\end{array}$ & IGT & HBP & HTG & HCH \\
\hline Overall & 54.3 & 9.3 & 11.1 & 9.8 & 10.3 & 9.2 \\
Isolated & 29.1 & 1.3 & 1.8 & 1.5 & 1.0 & 1.8 \\
$2 \times 2$ associations: & & & & & & \\
Type 2 diabetes & 3.8 & - & - & - & - & - \\
& $(5.1)$ & & & & & \\
IGT & 4.6 & - & - & - & - & - \\
HBP & $(6.0)$ & & & & & \\
& 2.2 & 0.1 & 0.3 & - & - & - \\
HTG & $(5.3)$ & $(0.9)$ & $(1.1)$ & & & \\
HCH & 3.0 & 0.2 & 0.2 & 0.1 & - & - \\
& $(5.6)$ & $(1.0)$ & $(1.1)$ & $(1.0)$ & & \\
\% Multiple & 2.4 & 0.2 & 0.1 & 0.1 & 0.5 & - \\
associations: & 17 & 40 & 37 & 56 & 51 & 45
\end{tabular}

a Entries are actual, crude prevalence rates (in percent). The numbers in parentheses are the expected prevalence rates of $2 \times 2$ associations, calculated as the product of the overall prevalence rates of the two members of the pair. The last line shows the percentage of all the cases of each condition occurring in combinations of three or more with other conditions
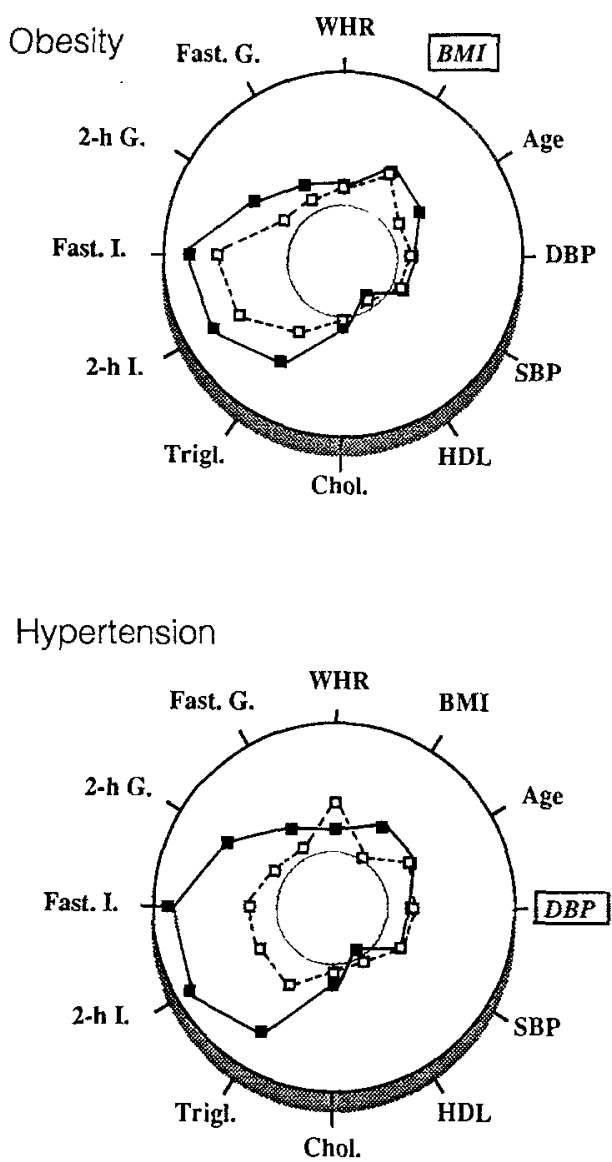

Fig. 1. Metabolic profile of obesity (top) and hypertension (bottom). The inner circle represents the mean value of each of the 12 variables (listed along the radii) in 1,049 healthy individuals; such mean values are set to be $100 \%$. The symbols are percent differences in each variable between the patients groups and healthy controls (i.e. mean group value/mean control value times 100 , plotted in log scale along the radii corresponding to the variable). Filled symbols and full lines identify the group of all subjects with obesity or hypertension; empty symbols and broken lines identify the subgroup of subjects with isolated obesity or hypertension (see the text for the definition of isolated). The variable in the box is the categorical (or coding) variable for the disease. $\mathrm{BMI}=$ body mass index; $\mathrm{WHR}=$ waist $/$ hip ratio; Fast. $\mathrm{G}=$ fasting plasma glucose concentration; $2-\mathrm{hr} \mathrm{G}=$ plasma glucose concentration $2 \mathrm{~h}$ after an oral glucose load; Fast. $\mathrm{I}=$ fasting plasma insulin concentration; 2 -hr I = plasma insulin concentration $2 \mathrm{~h}$ after an oral glucose load; $\mathrm{TG}=$ serum triglyceride level; Chol = serum total cholesterol level; HDL = serum high-density-lipoprotein cholesterol level; DBP = diastolic blood pressure; SBP = systolic blood pressure

(BMI) was calculated as weight (in $\mathrm{kg}$ ) divided by height (in meters) squared. Obesity was defined as a BMI $>27 \mathrm{~kg} / \mathrm{m}^{2}\left(>26 \mathrm{~kg} / \mathrm{m}^{2}\right.$ for women) [17]. Blood pressure was measured on the right arm of the seated participant following at least a 5 -min rest using a random-zero sphygmomanometer (Hawksley-Gelman, London, UK). Three readings were recorded of the systolic (first phase) and diastolic (fifth phase) measured to the nearest even digit, and the subject's blood pressure was defined as the average of the second and third reading. Hypertension was defined according to the Hypertension Detection and Follow-up criteria (diastolic blood pressure $\geq 95 \mathrm{~mm} \mathrm{Hg}$ and/or currently taking antihypertensive medication) [18].

Blood specimens were obtained following a $12-14 \mathrm{~h}$ fast for serum lipid, lipoprotein, and insulin and plasma glucose determinations. A 75-g glucose-equivalent load (Coladex or Orangedex, Cus- 
tom Laboratories, Baltimore, Md., USA) was then administered, and blood specimens were obtained $2 \mathrm{~h}$ later for plasma glucose and insulin measurements. Methods for measurement of glucose, lipid, lipoprotein, and insulin have been published previously [15]. Diabetes was diagnosed according to the criteria of the World Health Organization (WHO) (fasting plasma glucose levels $\geq 7.8 \mathrm{mmol} / 1$ or 2 nd h plasma glucose $\geq 11.1 \mathrm{mmol} / 1$ [19]. In previous reports, we have used National Diabetes Data Group (NDDG) criteria [2]. However, since the NDDG criteria do not have an unambiguous category for impaired glucose tolerance, we utilised the WHO criteria in the present report. The concordance between WHO and NDDG criteria for diagnosing diabetes in the San Antonio Heart Study is $98 \%$. Subjects who did not meet these criteria but who were currently being treated with oral antidiabetic agents or insulin were also considered to have diabetes. Impaired glucose tolerance (IGT) was defined as a fasting plasma glucose $<7.8 \mathrm{mmol} / 1$ and a 2nd $\mathrm{h}$ plasma glucose between 7.8 and $11.1 \mathrm{mmol} / \mathrm{l}$. Hypertriglyceridaemia was defined as a serum triglyceride concentration $>2.90 \mathrm{mmol} / \mathrm{l}$, and hypercholesterolaemia as a serum total cholesterol concentration $>6.50 \mathrm{mmol} / 1$.

\section{Statistical analysis}

Plasma insulin, glucose and triglyceride concentration values were $\log$ transformed to improve skewness. Group means were compared with the use of Student $\mathrm{s} t$-test. Simultaneous adjustment for other variables was carried out by multiple linear regression. Data are given as mean \pm SEM.

Type 2 diabetes

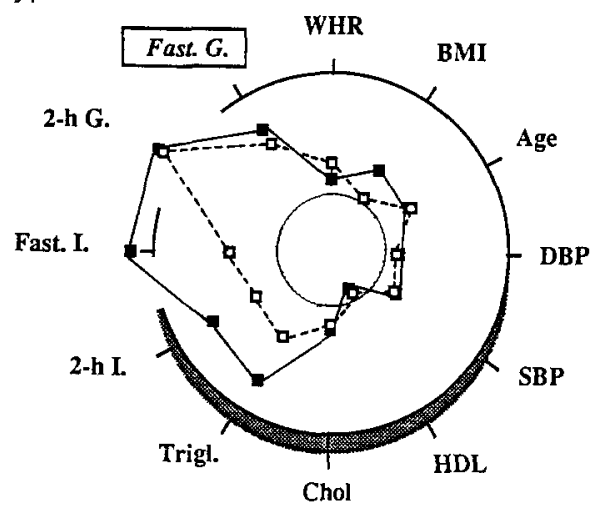

Impaired glucose tolerance

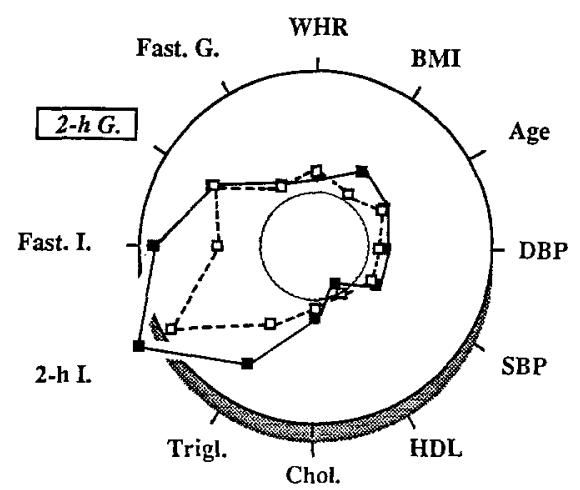

Fig.2. Metabolic profile of Type 2 (non-insulin-dependent) diabetes (top) and impaired glucose tolerance (bottom). All symbols as in Figure 1

\section{Hypertriglyceridaemia}
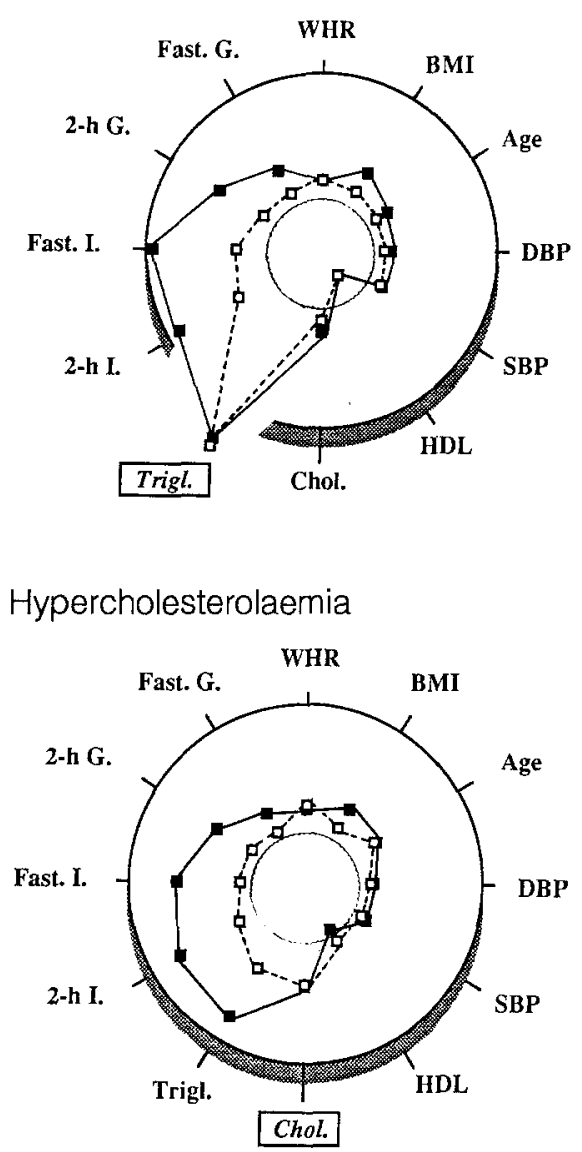

Fig. 3. Metabolic profile of hypertriglyceridaemia (top) and hypercholesterolaemia (bottom). All symbols as in Figure 1

\section{Results}

The population sample consisted of 2,930 subjects ( $43 \%$ men, 68\% Mexican-American), with a mean age of 42.9 years. Over one-half of the population sample was obese; each of the other five conditions was present in roughly $10 \%$ of all subjects (Table 1). Only $36 \%$ of all study subjects were 'normal' in that they were free of all six disorders. The crude prevalence rates of the six conditions in their 'pure' or isolated form, i. e. associated with none of the other five, were much lower than the overall prevalence rates, by $50 \%$ in the case of obesity, $5-10$ fold in the case of the others (Table 1). Two-by-two associations of isolated forms were even rarer, and in each case less frequent than expected by chance (Table 1 ). As a result, large proportions - ranging from $17 \%$ for obesity to $56 \%$ for hypertension - of the cases of each of the six conditions occurred in combination with three or more of the others.

When the six groups of patients consisting of all cases with a condition were compared with the respective subgroups in which the disease was present in isolation (Figs. 1-3), the profile of the 12 measured (physiological and metabolic) variables was still qualitatively abnormal in the 'isolated' condition subgroups. The clinical characteristics of these latter are shown in Table 2 together with those of the normal subjects, while Table 3 lists the corre- 


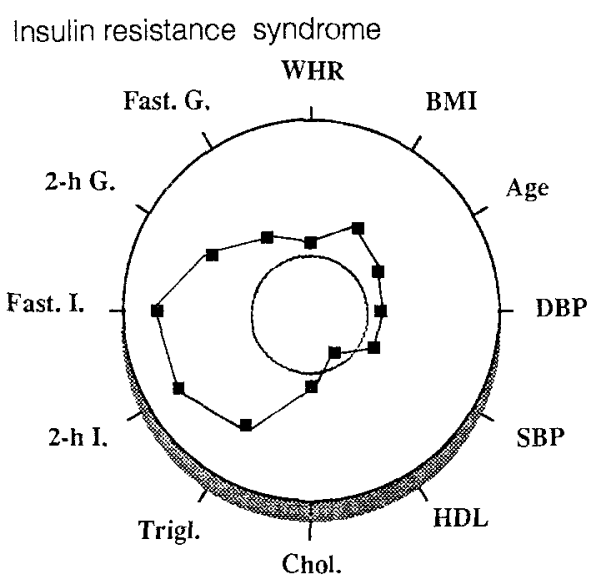

Fig. 4. Metabolic profile of all subjects with at least one of six conditions (obesity, hypertension, Type 2 (non-insulin-dependent) diabetes, impaired glucose tolerance hypertriglyceridaemia, hypercholesterolaemia). All symbols as in Figure 1

sponding metabolic measurements. Differences in age, sex or ethnicity ratio, and body mass index were present between each patient subgroup and the control subjects (Table 2$)$. The waist/hip ratio was significantly higher than normal in obese $(p<0.005)$, diabetic $(p<0.01)$, glucoseintolerant $(p<0.02)$, and hypertensive $(p=0.02)$, but not in hypertriglyceridaemic or hypercholesterolaemic, patients. Because age, gender, ethnic origin, and body mass were all found to have a significant statistical influence on one or more of the metabolic variables (data not shown), comparisons between each patient subgroup and the control population were carried out after adjusting, by multiple linear regression, for age, sex, ethnicity, and BMI. The results are reported in Table 4 in terms of percent deviations from the mean reference values. They show that, even after the adjustments, each of the six isolated condi- tions was characterised by significant changes in several of the metabolic variables in addition to the defining variable for the condition itself. Thus, raised blood pressure was present also in 'pure' diabetic, IGT, or obese subjects, while increased fasting and $2 \mathrm{nd} \mathrm{h}$ plasma glucose concentrations also occurred in 'pure' obese or hypertensive subjects. In particular, hyperinsulinaemia, fasting or post-glucose, was found in all patient groups (although in pure hypercholesterolaemia the adjusted difference from control subjects fell just short of full statistical significance, $p=0.11$ ).

When the 1,881 subjects with one or another disease combination (the 'insulin resistant' group) were compared with the 1,049 control subjects, all of the clinical and metabolic variables were significantly above normal (or below, in the case of serum HDL-cholesterol concentrations) (Fig. 4). Adjusting for age, sex, ethnicity, and BMI did not alter either the size or the level of statistical significance of the differences (Table 5).

In the control group, numerous simple correlations were present among the measured variables, clinical and metabolic alike. In particular, when the fasting or postglucose plasma insulin concentration was set to be the dependent variable in a multiple regression model, 23 and $53 \%$, respectively, of the variance was explained by the other 13 measured variables $(p<0.001)$. In the insulin resistant' group, $50 \%$ of the variability of fasting insulin, and $57 \%$ of that of post-glucose insulin, was statistically explained by the other measured variables $(p<0.001)$.

\section{Discussion}

The first result that stands out in the present analysis is the very high degree of overlap among the six conditions considered (obesity, Type 2 diabetes, hypertension, impaired glucose tolerance, hypertriglyceridaemia, and hyper-

Table 2. Characteristics of the groups studied ${ }^{2}$

\begin{tabular}{|c|c|c|c|c|c|c|}
\hline & $n$ & $\mathrm{M} / \mathrm{F}$ & MA/NHW & $\begin{array}{l}\text { Age } \\
\text { (years) }\end{array}$ & $\begin{array}{l}\text { BMI } \\
\left(\mathrm{kg} / \mathrm{m}^{2}\right)\end{array}$ & WHR \\
\hline Normal & 1.049 & $442 / 607$ & $601 / 448$ & $39.6 \pm 0.3$ & $22.8 \pm 0.1$ & $0.848 \pm 0.008$ \\
\hline Obese & 852 & $354 / 498$ & $630 / 222$ & $41.3 \pm 0.4$ & $31.1 \pm 0.1$ & $0.898 \pm 0.010$ \\
\hline Hypertensive & 44 & $21 / 23$ & $23 / 21$ & $50.0 \pm 2.0$ & $21.6 \pm 0.8$ & $1.246 \pm 0.258$ \\
\hline Glucose intolerant & 52 & $18 / 34$ & $36 / 16$ & $46.8 \pm 1.6$ & $23.4 \pm 0.4$ & $1.014 \pm 0.157$ \\
\hline Hypertriglyceridaemic & 29 & $24 / 5$ & $20 / 9$ & $41.0 \pm 2.3$ & $25.1 \pm 0.3$ & $0.931 \pm 0.012$ \\
\hline
\end{tabular}

${ }^{3} \mathrm{M} / \mathrm{F}=$ male/female ratio; MA/NHW $=$ Mexican-American/ non-Hispanic White ratio; BMI $=$ Body mass index; WHR $=$ waist/hip ratio

Table 3. Metabolic parameters of the normal, obese, Type 2 diabetic, hypertensive, glucose-intolerant, hypertriglyceridaemic, and hypercholesterolaemic subgroups ${ }^{\mathrm{a}}$

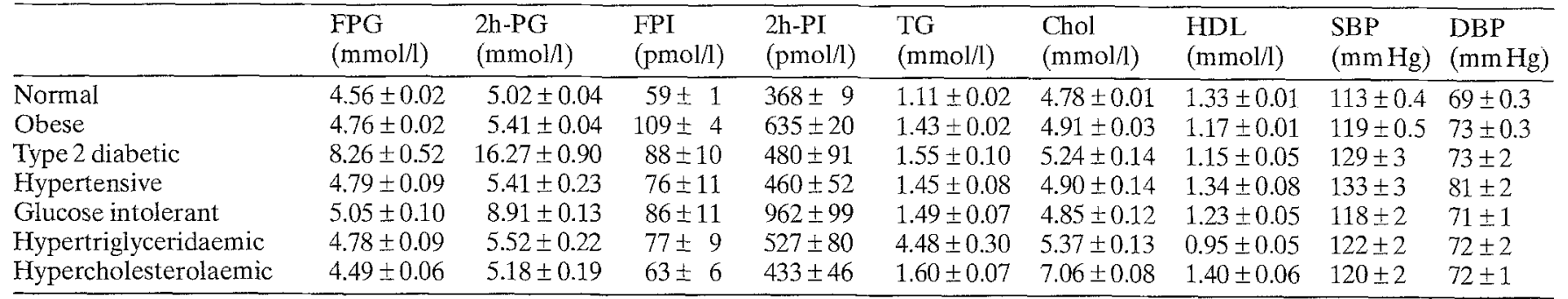

${ }^{a} \mathrm{FPG}=$ fasting plasma glucose; $2 \mathrm{~h}-\mathrm{PG}=2$-h plasma glucose; $\mathrm{FPI}=$ fasting plasma insulin; $2 \mathrm{~h}-\mathrm{PI}=2$ - $\mathrm{h}$ plasma insulin; $\mathrm{TG}=$ serum triglycerides; $\mathrm{Chol}=$ serum total cholesterol; $\mathrm{HDL}=$ serum $\mathrm{HDL}$-cholesterol; $\mathrm{SBP}=$ systolic blood pressure; $\mathrm{DBP}=$ diastolic blood pressure 
Table 4. Percent differences in metabolic parameters between the six patient subgroups and the control group ${ }^{\mathrm{a}}$

\begin{tabular}{lcccccc}
\hline & OB & Type 2 & HBP & IGT & HTG & HCH \\
\hline Fasting glucose & $+4^{\mathrm{a}}$ & $+66^{\mathrm{a}}$ & $+3^{\mathrm{a}}$ & $+10^{\mathrm{a}}$ & +3 & -2 \\
2-h glucose & $+6^{\mathrm{a}}$ & $+198^{\mathrm{a}}$ & -4 & $+76^{\mathrm{a}}$ & $+12^{\mathrm{a}}$ & 0 \\
Fasting insulin & $+80^{\mathrm{a}}$ & $+58^{\mathrm{a}}$ & $+35^{\mathrm{a}}$ & $+43^{\mathrm{a}}$ & $+24^{\mathrm{a}}$ & +20 \\
2-h insulin & $+49^{\mathrm{a}}$ & -5 & $+36^{\mathrm{a}}$ & $+143^{\mathrm{a}}$ & $+41^{\mathrm{a}}$ & +17 \\
Triglycerides & $+28^{\mathrm{a}}$ & $+13^{\mathrm{a}}$ & $+18^{\mathrm{a}}$ & $+26^{\mathrm{a}}+274^{\mathrm{a}}+37^{\mathrm{a}}$ \\
Total Chol. & $+2^{\mathrm{a}}$ & 0 & -4 & -3 & $+10^{\mathrm{a}}+43^{\mathrm{a}}$ \\
HDL-Chol. & $-13^{\mathrm{a}}$ & $-15^{\mathrm{a}}$ & -1 & $-11^{\mathrm{a}}-21^{\mathrm{a}}+3$ \\
SBP & $+4^{\mathrm{a}}$ & $+8^{\mathrm{a}}+13^{\mathrm{a}}$ & $+3^{\mathrm{a}}+4^{\mathrm{a}}+4^{\mathrm{a}}$ \\
DBP & $+5^{\mathrm{a}}$ & +2 & $+15^{\mathrm{a}}$ & +2 & +1 & $+4^{\mathrm{a}}$ \\
\hline
\end{tabular}

a Indicates that the percent change (from the control value) is significantly different from zero ( $p<0.05$ or less) after adjusting for age, sex, ethnicity, and BMI. Numbers in italics identify the classification variables. $\mathrm{OB}=$ obesity; Type 2 = Type 2 diabetes; $\mathrm{HBP}=$ hypertension; IGT = impaired glucose tolerance; HTG = hypertriglyceridaemia; $\mathrm{HCH}=$ hypercholesterolaemia; $\mathrm{SBP}=$ systolic blood pressure; $\mathrm{DBP}=$ diastolic blood pressure

cholesterolaemia), a degree perhaps not fully appreciated until now. Each condition is defined by a conventional cutoff value of a continuous variable (e.g., body mass, glucose concentrations, blood pressure, etc.) rather than by the presence of a unique feature. Therefore, the observed superimposition pattern is dependent upon the chosen cut-off points. Shifting one or the other diagnostic criterion is likely to cause only quantitative, not qualitative differences in the overlap pattern. However, a very different prevalence of one condition would probably change the rate of occurrence of dual or multiple combinations. With regard to this, it is pertinent to note that the prevalence of Type 2 diabetes in the biethnic population of San Antonio is higher than in most westernised societies, on account of the enrichment of the Mexican-American group with diabetic individuals [15]. Since obesity, especially of the truncal variety, also is particularly frequent in MexicanAmericans [17], the results of the present analysis may not fully extend to other populations.

Also striking is the observation that simple (two-bytwo) associations were all rarer than predicted by chance alone; this sort of spurious 'protection' against occurrence of two conditions together was actually the result of the high prevalence of triple or multiple combinations (Table 1). Thus, for all conditions but obesity, occurring as an isolated case in the cluster was an exceedingly infrequent event at the population level. One immediate practical corollary of these findings is that diagnosing any one of the six conditions in question should be sufficient indication to screen for the other five. Because of the extensive overlap, it was not surprising to find that each of the six conditions was characterized by multiple abnormalities (Figs. 1-3). More importantly, the analysis of the subgroups in which each condition was present alone revealed that, even in these isolated cases each categorical abnormality (e. g., blood pressure in hypertension) was accompanied by significant changes in several of the metabolic variables classifying other members of the sextet (after adjusting for age, gender and ethnic ratio, and BMI). Thus, lean, normotensive, normolipidaemic diabetic patients still had a significantly lower HDLcholesterol concentration and an increased systolic blood pressure value; lean, non-diabetic, normolipidaemic hypertensive patients also had slight fasting hyperglycaemia and hyperlipidaemia when compared with the control subjects (Table 4). These results, and the fact that the 12 measured variables showed a high degree of interrelatedness even in the group of healthy control subjects, suggest that the network of connections among the six conditions may simply be an amplification of normal links among the underlying physiological functions [5]. The physiological basis of several such relationships is well established. For example, a rise in plasma glucose levels can directly result from tissue refractoriness to insulin action on glucose uptake; elevated glycaemia then elicits a heightened insulin secretory response, which in turn is a stimulus for hepatic VLDL-triglyceride production [2022]. Also, hyperinsulinaemia may raise blood pressure by a variety of mechanisms including renal sodium conservation and adrenergic activation [23]. If, then, the physiologic system explored by these parameters is indeed a network, pulling one element out of the normal boundaries will act upon the connecting arms to drag other neighbouring elements into the 'abnormal' domain. For example, if a strong genetic pressure drives plasma glucose into the diabetic range, blood pressure and lipids will trail behind, occasionally crossing the diagnostic

Table 5. Clinical and metabolic characteristics of the insulin resistant group and their percent differences from the control group ${ }^{a}$

\begin{tabular}{|c|c|c|c|}
\hline & Mean \pm SEM & $\begin{array}{l}\text { Percent differ- } \\
\text { ence from controls }\end{array}$ & $p$ value \\
\hline Number & 1881 & - & \\
\hline $\mathrm{M} / \mathrm{F}$ & $815 / 1061$ & - & \\
\hline MA/NHW & $1395 / 481$ & - & \\
\hline Age (years) & $45.3 \pm 0.3$ & - & \\
\hline BMI $\left(\mathrm{kg} / \mathrm{m}^{2}\right)$ & $30.5 \pm 0.1$ & - & \\
\hline WHR & $0.932 \pm 0.012$ & $+15 \%$ & $<0.0001$ \\
\hline $\begin{array}{l}\text { Fasting glucose } \\
(\mathrm{mmol} / \mathrm{l})\end{array}$ & $5.53 \pm 0.05$ & $+5 \%$ & $<0.0001$ \\
\hline $\begin{array}{l}\text { 2-h Glucose } \\
(\mathrm{mmol} / \mathrm{l})\end{array}$ & $7.80 \pm 0.11$ & $+20 \%$ & $<0.0001$ \\
\hline $\begin{array}{l}\text { Fasting insulin } \\
(\mathrm{pmol} / \mathrm{l})\end{array}$ & $129 \pm 3$ & $+36 \%$ & $<0.0001$ \\
\hline $\begin{array}{l}\text { 2-h Insulin } \\
(\mathrm{pmol} / \mathrm{l})\end{array}$ & $787 \pm 18$ & $+37 \%$ & $<0.0001$ \\
\hline $\begin{array}{l}\text { Triglycerides } \\
(\mathrm{mmol} / \mathrm{l})\end{array}$ & $2.01 \pm 0.03$ & $+50 \%$ & $<0.0001$ \\
\hline $\begin{array}{l}\text { Total cholesterol } \\
(\mathrm{mmol} / \mathrm{l})\end{array}$ & $5.33 \pm 0.03$ & $+10 \%$ & $<0.0001$ \\
\hline $\begin{array}{l}\text { HDL-cholesterol } \\
(\mathrm{mmol} / \mathrm{l})\end{array}$ & $1.14 \pm 0.01$ & $-8 \%$ & $<0.0001$ \\
\hline $\mathrm{SBP}(\mathrm{mm} \mathrm{Hg})$ & $123 \pm 0.4$ & $+4 \%$ & $<0.0001$ \\
\hline $\mathrm{DBP}(\mathrm{mm} \mathrm{Hg})$ & $74 \pm 0.2$ & $+4 \%$ & $<0.0001$ \\
\hline
\end{tabular}

a The comparison with the control group is made after adjusting for age, sex, ethnicity, and BMI, and calculated at the mean population age (43 years) and BMI $\left(27.9 \mathrm{~kg} / \mathrm{m}^{2}\right)$ for a male Mexican-Americansubject. $\mathrm{M} / \mathrm{F}=$ male/female ratio; $\mathrm{MA} / \mathrm{NHW}=$ Mexican-American/non-Hispanic white; BMI = body mass index; WHR = waist $/$ hip ratio; $\mathrm{SBP}=$ systolic blood pressure; $\mathrm{DBP}=$ diastolic blood pressure 
threshold of clinical hypertension and dyslipidaemia. Thus, on a priori grounds it is highly unlikely that any of this kindred of disorders will occur in true isolation, i.e. with no changes (or opposite changes) in the tied metabolic/haemodynamic functions.

The other major finding of this study is that, while insulinaemia itself is not a classification variable for any disease, hyperinsulinaemia, fasting or post-glucose, was present in all the subgroups of isolated conditions. It was the common denominator of the sextet. Under most circumstances, a raised plasma insulin concentration implies the presence of insulin resistance, and, in fact, represents an adaptive response to the reduced sensitivity to the hormone [24]. Previous studies using the euglycaemic insulin clamp technique [25] have shown that insulin resistance is present in non-diabetic, normotensive obese subjects [26], in lean, normotensive patients with Type 2 diabetes [27] or impaired glucose tolerance [28, 29], in lean, normotensive hypertriglyceridaemic subjects [30], and in lean, nondiabetic, normolipidaemic hypertensive patients $[8,31]$. In these highly selected patient groups, the insulin resistance has been thought of as primary [9]. Direct evidence that pure, isolated hypercholesterolaemia may be associated with insulin resistance is lacking, but the data in Table 4 suggest that this might be the case. Thus, at least five of the six conditions considered here have already entered the list of primary insulin resistant states in humans. Therefore, the present data on hyperinsulinaemia very likely illustrate the relationship of insulin resistance with the physiological and metabolic changes found in the member conditions of the sextet. It is legitimate to collectively indicate the sextet as a primary insulin resistance syndrome (Fig. 4), in which different features (e. g., hyperglycaemia or high blood pressure) dominate the clinical picture in different patients. This concept is an extension of the insulin resistance syndrome hypothesised by Reaven [9], and alluded to by Lind et al. [32], and certainly is not exhaustive: other disorders with genetic imprint, insulin resistance and atherogenic potential may be included.

The question then arises: is insulin resistance one common result of the six conditions (e.g., via hyperglycaemia in Type 2 diabetes, or high blood pressure in hypertension), or is it a basic cellular defect, parent to the conditions? Available evidence appears to be insufficient to answer this question. Some information would favour a primacy of insulin resistance. Thus, at least in nondiabetic Pima Indians, in vivo insulin action is a familial characteristic [33]. Furthermore, non-diabetic relatives of Type 2 diabetic patients present hyperinsulinaemia [34] and insulin resistance [35], and hyperinsulinaemia predicts the subsequent development of Type 2 diabetes [36]. Parental history of Type 2 diabetes is associated with higher prevalence of hypertension and lipid abnormalities in non-diabetic probands [37]. Hyperinsulinaemic, but otherwise healthy, individuals have higher plasma glucose and lipid levels and blood pressure values [38]. In at least one variant of familial dyslipidaemic hypertension, hyperinsulinaemia is found that is not fully explained by obesity [39]. On the other hand, insulin resistance can be entirely acquired - as presumably are many cases of obesity in- duced by excess caloric intake - and yet display the full range of associated abnormalities of glucose and lipid metabolism and blood pressure. The present analysis of cross-sectional data cannot offer any clue as to the nature of the observed associations among diseases or the relation of each of them to insulin resistance. Genetic heterogeneity, environmental factors, and gene-environment interactions are known to determine the natural history of obesity, Type 2 diabetes, hypertension, and dyslipidaemias [40-44]. Their multiple associations may likewise reflect true genetic linkage, cause-effect relationships, or both. At present, it seems both accurate and prudent to state that the presence of insulin resistance in the sextet can have a variable value - of a predisposing or aggravating factor - in the different member diseases and, possibly, within the affected individuals of each disease.

Whatever the case, the general pattern of abnormalities in the insulin resistant group (Fig. 4) is a highly atherogenic risk profile, in support of the contention that this syndrome is a precursor of CVD. Longitudinal studies are needed to address what appears to be the crucial issue: is an insulin resistant individual 'bound' to develop a string of abnormalities ultimately leading to CVD?

Acknowledgement. This work was supported by grant HL 24799.

\section{References}

1. Sims EAH, Berchtold P (1982) Obesity and hypertension. Mechanisms and implications for management. JAMA 247: 49-52

2. National Diabetes Data Group (1979) Classification of diabetes mellitus and other categories of glucose intolerance. Diabetes 28 : $1039-1055$

3. Fuller JH (1985) Epidemiology of hypertension associated with diabetes mellitus. Hypertension 7 [Suppl. II]: II3-7

4. Nikkila EA (1984) Plasma lipid and lipoprotein abnormalities in diabetes. In: Jarrett RJ (ed) Diabetes and heart disease. Elsevier, Amsterdam, pp 133-167

5. Stamler J, Berkson D, Dyer A, Lindberg HA (1975) Relationship of multiple variables to blood pressure findings from four Chicago epidemiologic studies. In: Paul O (ed) Epidemiology and control of hypertension. Stratton, New York, pp 307-356

6. Modan M, Halkin H, Almog S, Lusky A, Eskol A, Shefi M, Shitrit A, Fuchs L (1985) Hyperinsulinaemia. A link between hypertension obesity and glucose intolerance. J Clin Invest 75: 809-817

7. DeFronzo RA, Ferrannini E (1982) The pathogenesis of non-insulin dependent diabetes. An update. Medicine 61: 125-135

8. Ferrannini E, Buzzigoli G, Bonadonna R, Giorico MA, Oleggini M, Graziadei L, Pedrinelli R, Brandi LS, Bevilacqua S (1987) Insulin resistance in essential hypertension. N Engl J Med 317:350357

9. Reaven GM (1988) Role of insulin resistance in human disease. Diabetes 37: 1595-1607

10. Castelli WP (1984) Epidemiology of coronary heart disease: the Framingham study. Am J Med 76 [Suppl. 2A]: 4-12

11. Stamler R, Stamler J (1979) Asymptomatic hyperglycemia and coronary heart disease. J Chron Dis 32: 829-837

12. Manson JE, Colditz GA, Stampfer MJ, Willett WC, Rosner B, Monson RR, Speizer FE, Hennekens CH (1990) A prospective study of obesity and risk of coronary heart disease in women. $\mathrm{N}$ Engl J Med 322: 882--889

13. Pyốrălá K (1979) Relationship of glucose tolerance and plasma insulin to the incidence of coronary heart disease: results from two population studies in Finland. Diabetes Care 2: 121-141 
14. Ducimetiere P, Eschwege E, Papoz L, Richard JL, Claude JR, Rosselin G (1980) Relationship of plasma insulin levels to the incidence of myocardial infarction and coronary heart disease mortality in a middle-aged population. Diabetologia 19: 205-210

15. Haffner SM, Stern MP, Hazuda HP, Pugh JA, Patterson JK (1986) Hyperinsulinaemia in a population at high risk for non-insulin-dependent diabetes mellitus. N Engl J Med 315: 220-224

16. Hazuda HP, Comeaux PJ, Stern MP, Haffner SM, Eifler CW, Rosenthal M (1986) A comparison of three indicators for identifying Mexican Americans in epidemiologic research: methodological findings from the San Antonio Heart Study. Am J Epidemiol 123: 96-112

17. Stern MP, Patterson JK, Mitchell BD, Haffner SM, Hazuda HP (1990) Overweight and mortality in Mexican Americans. Int J Obes 14: 623-629

18. Hypertension Detection and Follow-up Program Cooperative Group (1977) Blood pressure studies in 14 communities: a twostage screen for hypertension. JAMA 237: 2385-2391

19. World Health Organization Expert Committee (1980) Second Report on Diabetes Mellitus. Geneva, WHO, Tech. Rep. Ser. No. 646

20. Tobey TA, Greenfield M, Kraemer F, Reaven GM (1981) Relationship between insulin resistance, insulin secretion, very low density lipoprotein kinetics and plasma triglyceride levels in normotriglyceridemic man. Metabolism 30: 165-171

21. Reaven GM, Lerner RL, Stern MP, Farquhar JW (1967) Role of insulin in endogenous hypertriglyceridemia. J Clin Invest 46: $1756-1767$

22. Steiner G, Vranic M (1982) Hyperinsulinemia and hypertriglyceridemia, a vicious circle with atherogenic potential. Int J Obes 6 [Suppl. 1]: 117-124

23. Ferrannini E, DeFronzo RA (1989) The association of hypertension, diabetes, and obesity: a review. J Nephrol 1:3-15

24. DeFronzo RA (1988) The triumvirate: $\beta$-cell, muscle, liver: a collusion responsible for NIDDM. Diabetes 37: 667-687

25. DeFronzo RA, Tobin JD, Andres R (1979) Glucose clamp technique: a method for quantifying insulin secretion and resistance. Am J Physiol 237: E214-E223

26. Kolterman OG, Insel J, Saekow M, Olefsky JM (1980) Mechanisms of insulin resistance in human obesity. Evidence for receptor and postreceptor defects. J Clin Invest 65: 1272-1284

27. Groop LC, Bonadonna RC, Del Prato S, Ratheiser K, Zyck K, Ferrannini E, DeFronzo RA (1989) Glucose and free fatty acid metabolism in non-insulin dependent diabetes mellitus: evidence for multiple sites of insulin resistance. J Clin Invest 84: 205-213

28. Bogardus C, Lillioja S, Howard B, Reaven GM, Mott D (1984) Relationships between insulin secretion, insulin action and fasting plasma glucose concentration in non-diabetic and non-insulin-dependent diabetic subjects. J Clin Invest 74: 1238-1246

29. Lillioja S, Mott DM, Howard BV, Bennett PH, Yki-Jarvinen H, Freymond D, Nyomba BL, Zurlo F, Swinburn B, Bogardus C (1988) Impaired glucose tolerance as a disorder of insulin action: longitudinal and cross-sectional studies in Pima Indians. N Engl J Med 318: 1217-1225

30. Steiner G, Morita S, Vranic M (1980) Resistance to insulin but not glucagon in lean human hypertriglyceridemics. Diabetes 29 : 899-905
31. Shen DC, Shieh S-M, Fuh MT, Chen Y-DI, Reaven GM (1988) Resistance to insulin-stimulated glucose uptake in patients with hypertension. J Clin Endocrinol Metab 66: 580-583

32. Lind L, Jakobsson S, Lithell H, Wengle B, Ljunghall S (1988) Relation of serum calcium to metabolic risk factors for cardiovascular disease. Br Med J 297: 960-963

33. Lillioja S, Mott DM, Zawadzki JK, Young AA, Abbott WGH, Knowler WC, Bennett PH, Moll P, Bogardus C (1987) In vivo insulin action is familial characteristic in nondiabetic Pima Indians. Diabetes 36: 1329-1335

34. Haffner SM, Stern MP, Hazuda HP, Mitchell BD, Patterson JK (1988) Increased insulin concentrations in nondiabetic offspring of diabetic parents. N Engl J Med 319: 1297-1301

35. Eriksson J, Franssila-Kallunki A, Ekstrand A, Saloranta C, Widen E, Schalin C, Groop L (1989) Early metabolic defects in persons at increased risk for non-insulin-dependent diabetes mellitus. N Engl J Med 321: 337-343

36. Haffner SM, Stern MP, Mitchell BD, Hazuda HP, Patterson JK (1990) Incidence of type II diabetes in Mexican Americans predicted by fasting insulin and glucose levels, obesity, and body-fat distribution. Diabetes 39: 283-288

37. Haffner SM, Stern MP, Hazuda HP, Mitchell BD, Patterson JK, Ferrannini E (1989) Parental history of diabetes is associated with increased cardiovascular risk factors. Arteriosclerosis 9: 928-933

38. Zavaroni I, Bonora E, Pagliara M et al. (1989) Risk factors for coronary artery disease in healthy people with hyperinsulinaemia and normal glucose tolerance. $N$ Engl J Med 320: 202206

39. Hurt SC, Wu LL, Hopkins PN et al. (1989) Apolipoprotein, low density lipoprotein subfraction, and insulin associations with familial combined hyperlipidemia. Study of Utah patients with familial dyslipidemic hypertension. Arteriosclerosis 9: 335-344

40. Stunkard AJ, Sorensen TIA, Hanis C, Teasdale TW, Chakraborty R, Schull WJ, Schulsinger F (1986) An adoption study of human obesity. N Engl J Med 314: 193-198

41. Foster DW (1989) Diabetes mellitus. In: Scriver CR, Beaudet AL, Sly WS, Valle D (eds) The metabolic basis of inherited diseases, 6th edn. McGraw-Hill, New York, p384

42. Johnson BC, Epstein FH, Kjelsberg M (1965) Distribution and familial studies of blood pressure and serum cholesterol levels in a total community, Tecumseh, Michigan. J Chronic Dis 18: 147160

43. Iselius L, Morton NE, Rao DC (1983) Family resemblance for blood pressure. Hum Hered 33: 277-286

44. Grundy SM (1987) Disorders of lipids and lipoproteins. In: Stein $\mathrm{JH}$ (ed) Internal medicine, 2nd edn. Little, Brown and Company, Boston, pp 2035-2052

Received: 22 October 1990

and in revised form: 17 January 1991

Dr. E. Ferrannini

C.N.R. Institute of Clinical Physiology

Via Savi, 8

I-56100 Pisa

Italy 